\title{
High-frequency data from the U.S. Census Bureau during the COVID-19 pandemic: small vs. new businesses
}

\author{
Catherine Buffington $^{1} \cdot$ Daniel Chapman ${ }^{1,2} \cdot$ Emin Dinlersoz $^{1} \cdot$ Lucia Foster $^{1} \cdot$ John Haltiwanger $^{3}$
}

Published online: 1 July 2021

(c) This is a U.S. government work and not under copyright protection in the U.S.; foreign copyright protection may apply 2021

\begin{abstract}
Small businesses experienced very sharp declines in activity, business sentiment, and expectations early in the pandemic. While there has been some recovery since then, multiple indicators of small business performance remained substantially in the negative range early in 2021. These findings are from a unique high frequency, real time, survey of small employer businesses, the Census Bureau's Small Business Pulse Survey (SBPS). In contrast, results from the high frequency, real time, Business Formation Statistics (BFS) show there has been a surge in new business applications following an initial decline. Most of these applications are for likely nonemployers; however, there has also been a surge in new applications for likely employers, especially in Retail Trade (and especially Non-store Retailers). We compare and contrast the patterns from these two new high frequency data products that provide novel insights into the distinct patterns of dynamics for existing small businesses relative to new business formations.
\end{abstract}

Keywords COVID-19 $\cdot$ Small Business Pulse Survey $\cdot$ Business Formation Statistics

\section{Introduction}

In the early stages of the COVID-19 pandemic, the Census Bureau introduced new data products designed to capture its impact on the American economy and population

\footnotetext{
Any opinions and conclusions expressed herein are those of the authors and do not represent the views of the U.S. Census Bureau. All results in this paper use publicly available data from Census Bureau websites. The Census Bureau has reviewed the public domain products for unauthorized disclosure of confidential information and has approved the disclosure avoidance practices applied to this release. (Approval ID: CBDRB-FY20-259, CBDRB-FY-20-357, CBDRB-FY-20-214, CBDRB-FY21-094). We thank John Eltinge, Scott Ohlmacher, and Nick Orsini of the Census Bureau and Maurine Haver and Robert Parker for helpful comments. This paper is the shortened version of a Center for Economic Studies working paper with the title High Frequency Business Dynamics in the United States During the COVID-19 Pandemic.
}

\footnotetext{
Lucia Foster

Lucia.S.Foster@census.gov

1 U.S. Census Bureau, Washington, DC, USA

2 University of Maryland, College Park, USA

3 Department of Economics, University of Maryland, College Park, USA
}

(Buffington et al. 2021b provides an overview). We describe the results from two new business data products designed to provide geographically granular, timely, and high-frequency information about the impact of the COVID-19 pandemic on businesses: the Small Business Pulse Survey (SBPS) and the weekly and monthly Business Formation Statistics (BFS). ${ }^{1}$ We thus focus our attention on small businesses through the SBPS and potential new businesses through the business application series from the BFS.

Results from the first three phases of the SBPS, running from April 2020 through January 2021, show existing small businesses experienced very sharp declines in activity, overall sentiment, and expectations early in the pandemic, and that while these later became less negative, they were still in a substantially negative range by the first week of January $2021 .^{2}$ The patterns for new business applications from the BFS are in sharp contrast. After an initial decline, the BFS

\footnotetext{
1 These two novel public use data products can be found at https:// census.gov/businesspulsedata and https://www.census.gov/econ/bfs/ data.html. For more information on the SBPS see Buffington et al. (2021a). For more information on the high frequency BFS data produced during the pandemic see Dinlersoz et al. (2021) and Haltiwanger (2021).

2 The analysis in this paper covers the first three phases of the SBPS: April 26, 2020-June 27, 2020; August 9, 2020-October 12, 2020; and November 9, 2020-January 10, 2021.
} 
Table 1 Revenue and employment in two example sectors

\begin{tabular}{llll}
\hline Concept & Sector & Pre-pandemic & Pandemic \\
\hline Revenue & & $2019: \mathrm{Q} 4$ & $2020: \mathrm{Q} 4$ \\
& Finance and Insurance & $1,227,080$ & $1,226,517$ \\
& Accommodation Services & 68,574 & 38,681 \\
& & $2019:$ December & 2020 : December \\
& Food Services and Drinking Places & 65,085 & 51,346 \\
& & $2020:$ January & $2021:$ January \\
& & $6,476.3$ & $6,525.0$ \\
& Finance and Insurance & $13,871.5$ & $10,967.8$ \\
\hline
\end{tabular}

Notes Revenue in millions of dollars, not seasonally adjusted. Employment in thousands, not seasonally adjusted

Sources Revenue: Quarterly Services Survey and Monthly Retail Trade Survey. Employment Employment Situation for January 2021

shows a strong surge in new business applications both for those that are likely to lead to a business with employees ("employers") and those that are likely to become businesses without employees ("nonemployers"). In fact, 2020 is the highest year for business applications since the series started in 2004, with most of this surge occurring in the second half of 2020 .

There is substantial sectoral variation evident for both existing small businesses and business applications. Small businesses in some service sectors have been especially hard hit, which we highlight by focusing on two extremes in our discussion of the SBPS: Finance and Insurance, and Accommodation and Food Services. Small businesses in Accommodation and Food Services show much more negative outcomes than those in Finance and Insurance. These results are consistent with official statistics on revenue and employment. As shown in Table 1, revenue for Finance and Insurance was little changed comparing 2020:Q4 and 2019:Q4, but that is not the case for the components of Accommodation and Food Services. Moreover, employment grew slightly in Finance and Insurance (by about 50,000 jobs) but fell by about 3 million in Accommodation and Food Services over 2020. ${ }^{3}$ Even so, small businesses in Finance and Insurance show no indicators of positive net growth, business sentiment, and expectations through Phase 3, even though the overall Finance and Insurance sector has largely recovered by early 2021 .

Turning to business applications, there has been an unprecedented increase in applications in the Retail Trade sector, particularly in Non-store Retail Trade, which

\footnotetext{
3 As further context for the overall size of these two sectors, according to the 2019 County Business Patterns, there are about 476,000 establishments in Finance and Insurance and about 741,000 establishments in Accommodation and Food Services.
}

includes e-commerce business activity. The patterns of sectoral changes differ for business applications that are likely employers and those that are likely nonemployers. New applications in the Retail Trade and Professional, Scientific, and Technical sectors have surged for both types of applications. In the SBPS, small businesses in Retail Trade have been hit about as hard as those in Accommodation and Food Services. Taken together, this suggests that the pandemic may lead to lasting structural changes in the economy.

The pandemic has a differential impact on existing small businesses and new business formations in terms of geography. For existing small businesses, the differential impact across states diminishes over time. Moreover, there is less persistence in state rankings of business sentiment than we

Table 2 Overview of content

\begin{tabular}{|c|c|c|}
\hline Concept & Phase 1 & Phases 2 and 3 \\
\hline Overall effect & Overall effect & Overall effect \\
\hline \multirow[t]{8}{*}{ Operations } & Total revenue & Total revenue \\
\hline & Revenue change & Revenue change \\
\hline & Temporary closures & Temporary/permanent closures \\
\hline & Change in employees & Change in employees \\
\hline & & Rehiring employees \\
\hline & Change in hours & Change in hours \\
\hline & & Remote work \\
\hline & & Online platforms \\
\hline \multirow[t]{5}{*}{ Challenges } & Supply chain & Supply chain/other disruptions \\
\hline & Shift in production & \\
\hline & Carry-out/Curbside & \\
\hline & & Operating capacity factors \\
\hline & & Operating capacity change \\
\hline \multirow[t]{5}{*}{ Finance } & Cash on hand & Cash on hand \\
\hline & Missed loans & Missed loans \\
\hline & Missed other & Missed other \\
\hline & Requested assistance & Requested assistance \\
\hline & Received assistance & Received assistance \\
\hline \multirow[t]{2}{*}{ Outlook } & & Future needs \\
\hline & Return to normal & Return to normal \\
\hline
\end{tabular}


see in sectoral rankings. The initial decline in business application activity, which started March 2020, is concentrated in states in the Northeast and the West, but the initial business application recovery is particularly concentrated in states in the South and the Midwest.

\section{Small business pulse survey}

Small employer businesses are an important part of the economy: $47 \%$ of workers at employer businesses work at small businesses and small businesses comprise about $81 \%$ of establishments and $99 \%$ of firms (2018 Business Dynamics Statistics). ${ }^{4}$ Moreover, many COVID-19 relief policies target small businesses. By the end of Phase 1 (late June 2020) of SBPS, $72.4 \%$ of SBPS respondents report having received financial assistance from the Paycheck Protection Program (PPP) and 21.3\% report having received financial assistance through Economic Injury Disaster Loans (EIDL).

The SBPS target population includes all single-location employer businesses with 1-499 employees and $\$ 1000+$ revenue that responded to the 2017 Economic Census and reported an email address. The survey divides these businesses equally across the nine weeks of each phase of the survey; about 100,000 emails are sent out each week to businesses asking them to participate in the survey. Each of the nine subsamples is used only once in each phase but are reused across phases (thus some businesses may respond in more than one phase). The response rate is about $25 \%$ and the results are re-weighted to be nationally representative using the survey weights (see Box 1). ${ }^{5}$

Box 1 Interpreting estimates
Care must be taken when comparing estimates from the SBPS over time. Differences between estimates may be attributed to sampling or nonsampling error, rather than to differences in underlying economic conditions. The SBPS initially weights businesses based on the number of eligible businesses within each state-subsector (by state by 3-digit NAICS); weights are then adjusted for survey-non-response prior to tabulation and publication. Businesses are assigned into one of nine-week groups by first sorting businesses using MSA and 2018 annual payroll, and then assigning them systematically across the nine-week groups. The initial weights are adjusted weekly for survey nonresponse to generate representative estimates at the national, sectoral, and employment size class levels. Weights are not adjusted to state totals, and therefore, care should be taken in interpreting state results.

In addition, some changes were made to questions and responses over time. In the fourth week of Phase 1, the Expectations question is amended to add the phrase "relative to one year ago" and the word "usual" is replaced with "normal." At the start of Phase 2, the categories "This business has returned to its normal level of operations" and "This business has permanently closed" are added as responses.

Potential selection bias may also be present. As outlined in Buffington et al. (2020), sources of non-response bias may be due to: non-response bias due to business closures; reliance on businesses that have email addresses; willingness of businesses to participate through email; sample reliance on single-location businesses that might be effected and respond differently than multi-locations businesses; willingness of businesses that sought federal assistance to respond to a survey from a federal source; greater likelihood of responses from businesses adversely impacted by the pandemic; and possibly low representation of very young businesses in the sample. Furthermore, in the sectoral comparisons, we drop three sectors collected in the SBPS due to the prevalence of suppressed cells. Differences between the sectors are reported at the 90 percent significance level using published standard errors.

The survey content was developed in partnership with eight interested stakeholders ${ }^{6}$ and varies over phases (with some concepts retained over all phases and some changing concepts, see Table 2 for an overview). The survey starts by asking about the overall effect of the pandemic on the business, then asks more detailed questions about operations, challenges, finances (including requests for and receipts of federal assistance), and closes with a question about the future analogous to the opening question. Many of the questions have checkbox responses determining whether a business is impacted (and some capture the degree of impact). ${ }^{7}$

\footnotetext{
${ }^{6}$ The Small Business Administration, the Federal Reserve Board of Governors, International Trade Administration, Minority Business Development Agency, Bureau of Transportation Statistics, National Telecommunications and Information Administration, Office of Tax Analysis of the Treasury Department, and the Bureau of Labor Statistics.

7 There were many other surveys conducted during the COVID-19 pandemic with similar concepts, we discuss a few and highlight the Business Response Survey (BRS) from the Bureau of Labor Statistics (BLS). BLS conducted one phase of the BRS July-September 2020 asking businesses about the impact of the pandemic and their responses through questions over three areas: "(1) business experiences and payroll decisions, (2) worker benefits and their ability to
}

${ }^{4}$ These refer only to employer businesses; there are also nonemployer businesses. To give a sense of their relative magnitudes: according to the Business Dynamics Statistics there are 5.3 million employer firms in the U.S. in 2018; according to the Nonemployer Statistics Demographics there are about 26 million nonemployer firms in 2017.

5 The reliance on email was driven by operational constraints due to the pandemic. See Buffington et al. (2020) and Small Business Pulse Survey Data (https://www.census.gov/data/experimental-data-produ cts/small-business-pulse-survey.html) for a more complete discussion of this and the methodology. 


\section{Overall Sentiment Index}

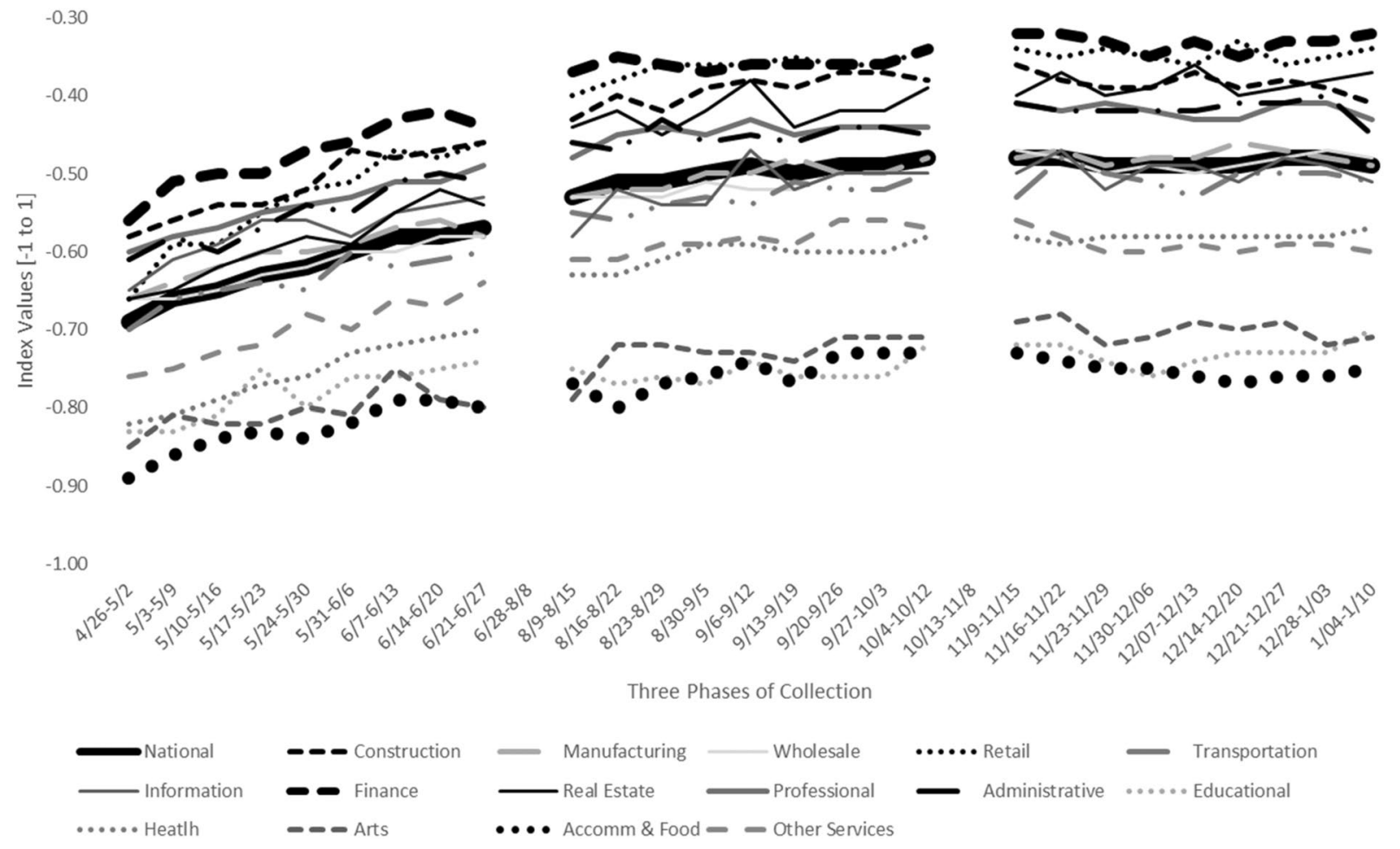

Fig. 1 Business overall sentiment. Source Authors' calculations from Small Business Pulse Survey

Before turning to the results, we note caveats outlined in Buffington et al. (2020) regarding potential selection bias in the survey responses (see Box 1). Briefly these include: nonresponse bias due to business closures; reliance on businesses that have email addresses; willingness of businesses to participate through email; sample reliance on single-location businesses that might be effected and respond differently than multilocations businesses; willingness of businesses that sought federal assistance to respond to a survey from a federal source; greater likelihood of responses from businesses adversely impacted by the pandemic; and possibly low representation of very young businesses in the sample. Furthermore, in the sectoral comparisons, we drop three sectors collected in the SBPS due to the prevalence of suppressed cells. We highlight results from five core concepts from the first three phases of the SBPS (for a fuller set of results see Buffington et al. (2021a)).

\section{Footnote 7 (continued)}

telework, and (3) whether a business received a loan or a grant from the government tied to the payroll." BRS: https://www.bls.gov/brs/ methods/technical-notes.htm.

\subsection{Business sentiment and revenues}

Business sentiment is collected in the question, "Overall, how has this business been affected by the Coronavirus pandemic?" with checkbox responses ranging from large negative, negative, no effect, positive, to large positive. The phrasing of the question is intended to capture a holistic assessment of the impact and the time frame is openended. Responses are summarized in the Overall Sentiment Index (OSI) which translates the responses to the overall sentiment question into an index with values ranging from -1 (most negative impact) to +1 (most positive impact). Figure 1 shows the OSI over three phases of the SBPS for the national average and sectors. Starting with the national results, the OSI is everywhere negative reflecting the fact that only a small portion of businesses have seen a positive impact (about $6.4 \%$ by the last week of Phase 3 ). The OSI index rises steadily over Phase 1 , rises slightly less over Phase 2, and flattens in Phase 3.

Similarly, the sectoral numbers are everywhere negative but decreasing in negativity over time (especially in Phases 1 and 2). Cross-sectoral differences grow over time: the average maximum-minimum difference rises from 0.35 in Phase 1 to 0.42 in Phase 3 . The ranking of the sectors is relatively stable over time: Finance and Insurance, Construction, and Retail Trade are consistently at the top of the distribution; 
Fig. 2 Revenue, employment, and hours changes, national. Source Authors' calculations from Small Business Pulse Survey. Notes RevUp $=$ Revenue increased in last week, $\operatorname{RevDn}=$ Revenue decreased in last week. Analogous definitions for Employment (EmpUp, EmpDn) and Hours (HrUp, $\mathrm{HrDn})$
Revenue, Employment, and Hours Changes: National

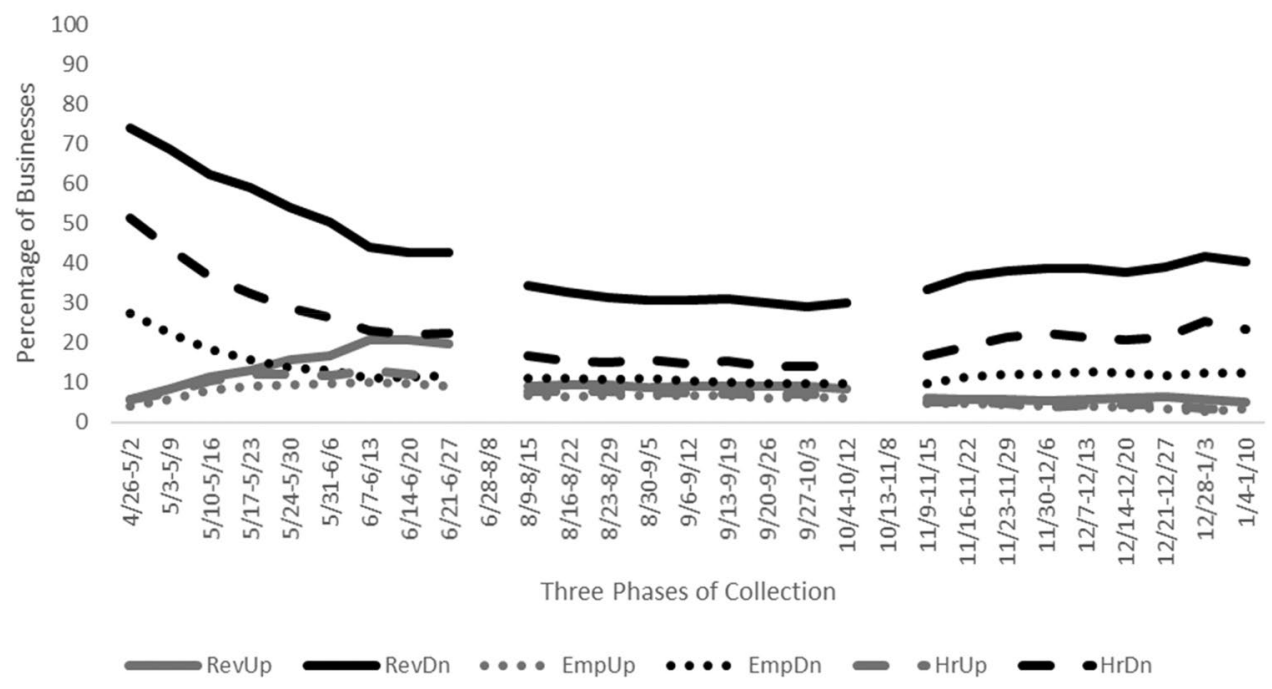

Arts, Entertainment, and Recreation; Educational Services; and Accommodation and Food Services are consistently at the bottom. A common characteristic for the sectors at the bottom of the distribution is the importance of in-person contact for their operations. At the end of Phase 3, 64.9\% of businesses in Accommodation and Food Services have a large negative effect as compared to $13.7 \%$ of business in Finance and Insurance. ${ }^{8}$

Another indicator of the status of businesses is change in revenue. The survey asks "In the last week, did this business have a change in operating revenues/sales/receipts, not including any financial assistance or loans?" with checkbox responses "Yes, increased," "Yes, decreased," and "No." In the first week of Phase 1,74.0\% of businesses saw a decrease in their revenue and 5.9\% saw an increase. The share of businesses with decreases falls and the share of increases rises so that by the last week of Phase $1,42.6 \%$ of businesses saw a decrease in their revenue and $19.7 \%$ saw an increase. In Phase 2, the shares level off with the share of businesses with decreases exceeding that with increases. Finally, in Phase 3 there is a general worsening, mostly driven by increasing shares of businesses with declines-see the solid lines in Fig. $2 .^{9}$

This pattern over the three phases is repeated in the Finance and Insurance and Accommodation and Food Services sectors but with some important differences across the sectors. ${ }^{10}$ The

\footnotetext{
8 These differences are significant at the $90 \%$ confidence level.

9 The BRS finds that $56 \%$ of establishments had decreases in demand for their goods or services but that $13 \%$ of establishments had increases in demand for their goods or services.
}

shares start off relatively similar: in the first week of Phase 1, 74.6\% of businesses in Accommodation and Food Services have decreases in revenue ( $8.4 \%$ have increases) and $67.8 \%$ of businesses in Finance and Insurance have decreases in revenue (3.2\% have increases). By the last week of Phase 3, Accommodation and Food Services is the sector with the highest percentage of businesses with a decrease in revenues $(56.1 \%)$, while Finance and Insurance has one of the lowest percentages of businesses with decreases $(22.1 \%)$. More businesses in Finance and Insurance have no change in revenues (73.8\%) than in Accommodation and Food Services (36.3\%) - see the solid lines in Fig. 3. The distribution of businesses with declining revenues becomes increasingly disperse across sectors over the phases (the average difference between the maximum and the minimum rises from 20 percentage points in Phase 1 to 38 percentage points in Phase $3)$. The SBPS collects information on challenges that impact capacity, which indicates that the physical distancing of customers is particularly important for Accommodation and Food Services but not for Finance and Insurance.

\subsection{Changes in employment and hours}

Analogous to the revenue question, the survey collects the percentage of businesses that change employment and hours (and whether the changes were increases or decreases). In the first week of Phase 1,27.5\% of businesses saw a decrease and $4.2 \%$ saw an increase in employment (68.2\% of businesses had no change). Similar to the revenue pattern over all three phases, the percent of businesses with decreases in

\footnotetext{
10 The differences between Finance and Insurance and Accommodation and Food Services are significant over all weeks over all questions except weeks 5 and 8 for decreasing revenue and weeks 20-23 for increasing revenue. See Box 1 for discussion.
} 


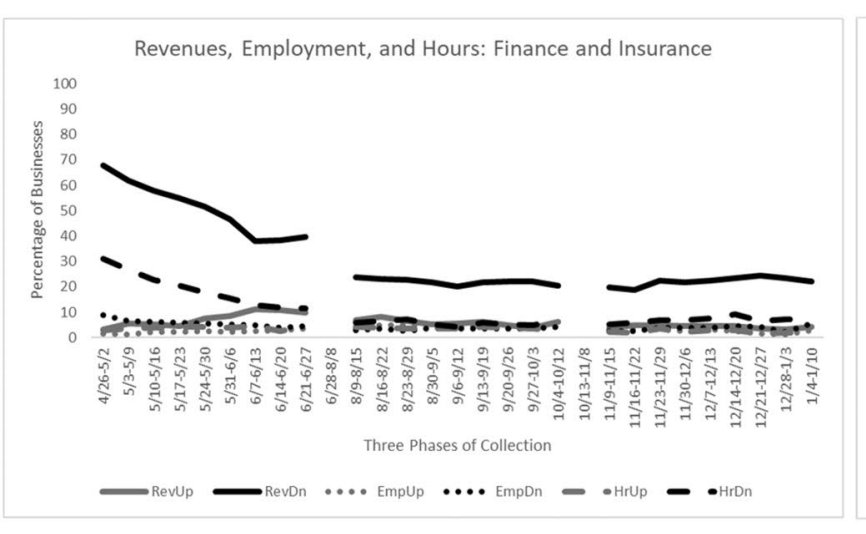

Fig. 3 Revenue, employment, and hours changes, two sectors. Source Authors' calculations from Small Business Pulse Survey.

Notes RevUp $=$ Revenue increased in last week, RevDn $=$ Rev-

employment falls over Phase 1 while the percent of businesses with increases rises slightly, they become more similar in Phase 2 before diverging in Phase 3. By the last week of Phase 3,12.4\% decreased and 3.4\% increased employment $(84.1 \%$ of businesses had no change) — see the dotted lines in Fig. 2. ${ }^{11}$

Comparing revenue changes to employment changes (the solid lines to the dotted lines) reveals that the average gap between the percentage of businesses with revenue-employment increases falls over time from 6.4 percentage points in Phase 1 to 1.9 in Phase 3. By contrast, the average gap for businesses with revenue-employment decreases falls over Phase 1 from 39.1 percentage points to 20.7 in Phase 2, before rising to 26.7 in Phase 3. These patterns are suggestive of labor hoarding (but recall that we do not know the relative sizes of these decreases in revenue and employment). The patterns may also reflect businesses participating in the PPP program trying to retain eligibility for loan forgiveness by maintaining employees.

Turning to our two example sectors, while $89.6 \%$ of Finance and Insurance businesses have no change in employment in the first week of Phase 1, only $45.4 \%$ of Accommodation and Food Services business report no change. ${ }^{12}$ The larger percentage of businesses reporting changes in Accommodation and Food Services are both on the negative side (47.2\% have decreasing as compared to $8.7 \%$ in Finance and Insurance) and the positive side ( $7.4 \%$ versus $1.7 \%)$. By the last week of Phase 3, 26.7\% of businesses in Accommodation and Food Services have declining employment as

\footnotetext{
11 The BRS found that $52 \%$ of establishments told employees not to work at some point during the reference period but slightly more than half of these continued to pay some or all of their employees while they were not working.

12 Differences between the two sectors are significant except for increasing employment for most weeks in Phase 3.
}

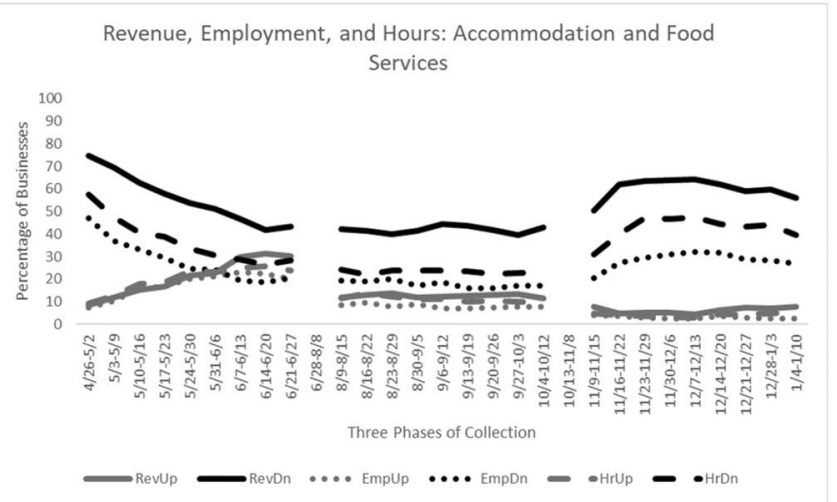

enue decreased in last week. Analogous definitions for Employment (EmpUp, EmpDn) and Hours (HrUp, HrDn)

compared to $5.5 \%$ of businesses in Finance and Insurancesee the dotted lines in Fig. 3.

Businesses in Accommodation and Food Services tend to adjust employment (and mostly on the decreasing margin) more than do businesses in Finance and Insurance. ${ }^{13}$ The correlations between revenue changes and employment changes are higher in Phase 1 than in Phases 2-3 for all sectors. Focusing on the two sectors, the correlation for Finance and Insurance drops from 0.92 in Phase 1 to 0.23 in Phases 2-3. By contrast, the correlation for Accommodation and Food Services hardly changes dropping from 0.98 in Phase 1 to 0.96 in Phases 2-3. Part of the difference in employment adjustments likely reflects the greater prevalence of remote work in Finance and Insurance sector reported in the SBPS. ${ }^{14}$

We see the same general patterns for hours that we saw for revenue and employment, with the percentage of businesses with changes in hours lying between the percentage of businesses with changes in revenue and employment (see Fig. 2, dashed lines). ${ }^{15}$ At the start of Phase $1,31.2 \%$ of businesses in Finance and Insurance have decreasing hours as compared to 57.6\% in Accommodation and Food Services. By the last week of Phase 3, 7.3\% of business in Finance and Insurance have a decline in hours as compared to $39.4 \%$ of businesses in Accommodation and Food Services (these differences across sectors are statistically significant).

Adding up the indicators of employment adjustments and hours adjustment, the share of small businesses that

\footnotetext{
${ }_{13}$ Using data from late March-early April, Bartik et al. (2020) find a similar sectoral pattern.

$1421.7 \%$ of businesses in Accommodation and Food Services report remote work as compared to $72.4 \%$ in Finance and Insurance in the last week of Phase 3.

15 The BRS finds $30 \%$ of establishments reduced employee hours but $5 \%$ of establishments increased employee hours.
} 
Fig. 4 Expectations (January 4-10, 2021). Source Authors' calculations from Small Business Pulse Survey
Expected Time Until Return to Normal Level of Operations: Sectoral

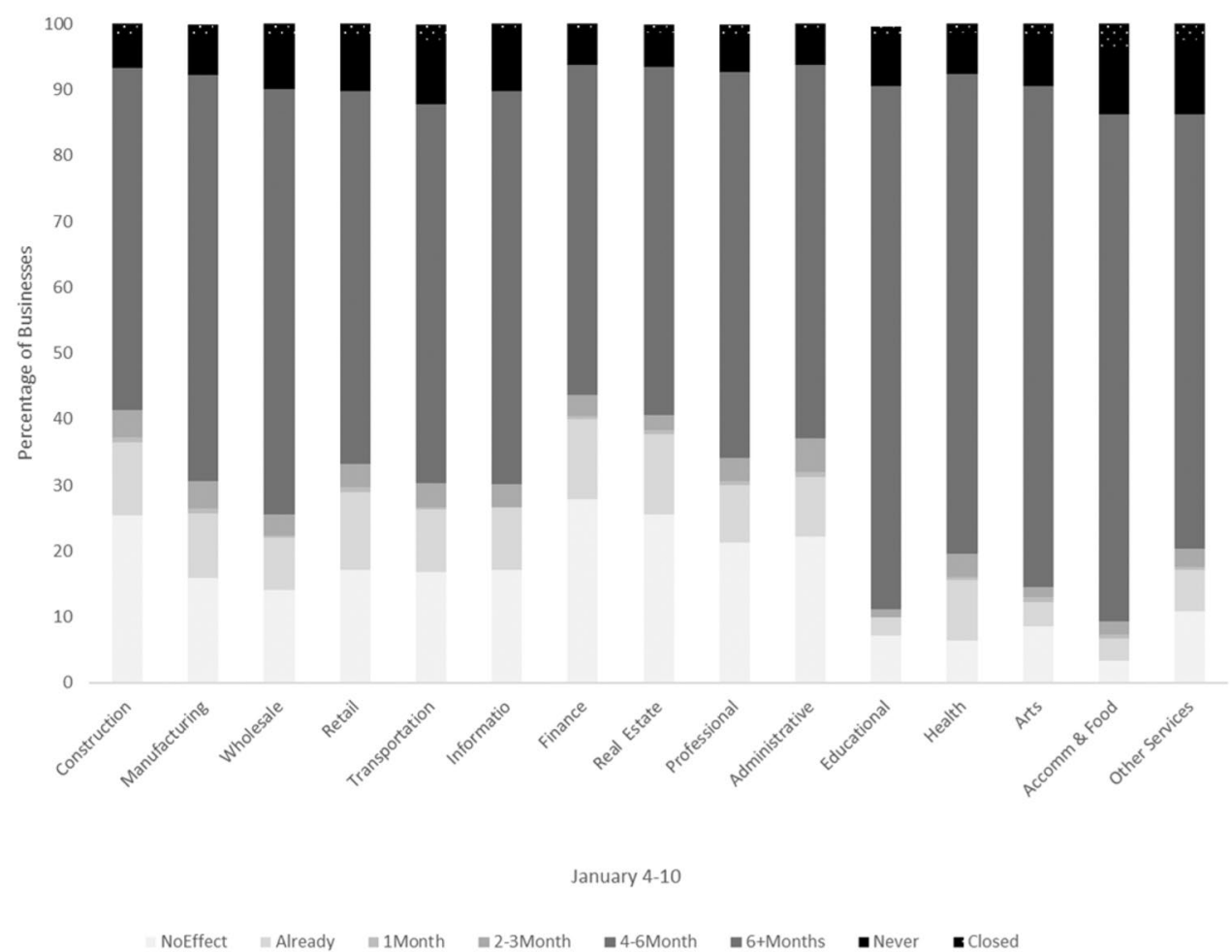

indicated they reduced employment or hours is $79 \%$ in the last week of April which is slightly more than those that indicated a decline in revenue (74\%). While many small businesses likely reduced both employment and hours, these patterns help make the case that the overall patterns of labor adjustments (hours or employment adjustments) echo those for revenue. In summary, for all three measures and all three samples, Phase 1 shows a rising share of businesses with increases in revenue, hours, employment and falling share of businesses with decreases in these concepts (yielding the pincer shape). In Phase 2, the shares level off with the share of businesses with decreases exceeding those with increases (the exception is employment in Finance). Finally, in Phase 3 there is a general worsening mostly driven by increasing shares of businesses with declines.

\subsection{Expectations}

The final question on the survey concerns expectations, asking: "In your opinion, how much time do you think will pass before this business returns to its normal level of operations relative to one year ago?" The responses include little/no effect, already back to normal, varying durations ( 1 month or less up to more than 6 months), never, and closed. ${ }^{16}$ Over time, the percent of businesses that expect a return to normal in the medium-term (2-6 months) has fallen (from 51.8\% in the first week of Phase 1 to $18.6 \%$ in the last week of Phase 3). This reflects greater percentages of businesses with expectations in the short-term and the long-term. The increases in percentages of businesses with short-term expectations rises in Phases 1-2 before falling slightly in Phase 3, driven mostly by "no impact" and "already back to normal." The percentage with long-term expectations rises in Phases 1 and 3 (and holds flat in Phase 2), driven mostly by the rise in " 6 months or more." 17 This shift towards a greater share of small businesses in Phase 3 expecting 6 months or more before a return to normal is striking given the substantial recovery in the overall economy during this time.

\footnotetext{
$\overline{16}$ See Box 1 for a discussion about changes in the questions and responses over the phases.

${ }^{17}$ Early in the pandemic, Bartik et al. (2020) find 50\% of small businesses expect the crisis to last until at least the middle of June. In fall 2020, Bloom et al. (2021) find businesses with 20 or more employees are expecting a return to normal level of sales by 2021:Q2; smaller businesses expect a longer time period until a return to normal and nonemployer businesses have the most pessimistic expectations. A December 2020 NFIB survey finds $36 \%$ of businesses expect a return to normal in 2022.
} 
We show sectoral differences in expectations for a point in time in Fig. 4. Here we stack the responses from more positive (little/no effect, already back to normal), to varying durations, to never, and closed. Finance and Insurance has relatively more businesses that were either not impacted, little impact, or already back to normal. Compare this to Educational Services, Arts and Entertainment, and Accommodation and Food Services which have relatively lower percentages of businesses who had little/no effect or are already back to normal.

Now we narrow our focus to our two example sectors. For both, there are smaller percentages of businesses with medium term expectations over time. Focusing on the last week of Phase 3, 40.4\% of businesses in Finance and Insurance expect a return to normal level of operations over the shorter horizon, as compared to $7.3 \%$ of businesses in Accommodation and Food Services. At the other extreme, $43.8 \%$ of businesses in Finance and Insurance expect a return to normal to take place over the longer horizon, as compared to $76.8 \%$ of businesses in Accommodation and Food Services.

In a K-shaped recovery some groups are already moving on an upward path in recovery; but others are on a downward or stalled path. The patterns in the SBPS are consistent with a K-shaped recovery both within and between sectors. For small businesses, there has been no sector exhibiting a positive range in all indicators. This persistent negativity holds even in sectors where indicators of all business activity including large businesses have shown a recovery. Moreover, some sectors remain especially weak for small businesses.

\subsection{Results by geography versus sector}

In considering results by geography, it is important to keep in mind that the pandemic impacted local areas at varying intensities and with different timing. Differences in the pace of infection likely influenced the pace of economic activity (see, e.g., Goolsbee and Syverson 2020). Relatedly, differing state and local policies likely impacted business activity. ${ }^{18}$

We examine the patterns in overall sentiment and changes in revenue in comparison with sectoral results and find differences in dispersion and persistence. For dispersion, we first compare the coefficient of variation for the overall sentiment for sectors and states over time. Sectors exhibit a higher coefficient of variation in overall sentiment index compared to states in all phases and weeks. Moreover, sectoral dispersion rises over time while state dispersion is much flatter. We next compare dispersion in the percentage of businesses with declining revenues. The average gap

\footnotetext{
18 Nonresponse bias and adjustments may also be important. See discussion in Box 1.
}

between the maximum and minimum share of businesses for sectors and states are relatively close to each other in Phase 1 (about 20 percentage points for sectors and about 25 percentage points for states), but this gap widens for sectors (to 38 percentage points) and narrows for states (to 23 percentage points) in Phase 3.

Geographic and sectoral differences in persistence of business sentiment are also instructive. The correlation between the first week of Phase 1 and the last week of Phase 3 for OSI is 0.90 for sectors but only 0.54 for states. We also find that $60 \%$ of the sectors remain in the same quintile as their starting place (for example, Finance and Insurance is in the highest quintile in the first and last weeks), but only $27 \%$ of the states remain in the same quintile as their starting place (for example, New York is in the lowest quintile in the first and last weeks). Even so, there is some stickiness for states; no state transitions from the top to the bottom quintile or vice versa.

\section{Business formation statistics}

While existing small businesses have experienced persistent negative outcomes over the course of pandemic through January 2021, the COVID-19 recession has also altered the landscape for potential entrepreneurs in 2020, and into the foreseeable future as the economy continues to adjust to potentially a new normal. New business applications fell sharply during March and April 2020, but there has been an unprecedented surge in business applications starting in May 2020. The time-series patterns for business applications have also exhibited strong geographic and sectoral disparities. These patterns are from the newly released high frequency BFS series.

The BFS was originally released as an experimental quarterly dataset for public use in $2018 .{ }^{19}$ The BFS uses applications for Employer Identification Numbers (EINs) obtained from the Internal Revenue Service (IRS) to construct nationwide, industry-level and state-level time series for applications made for new businesses, as well as actual and projected employer business formations originating from these applications. The application process for new EINs is largely online and automated so the application processes should not have been impacted by restrictions associated with the pandemic.

The BFS was released continuously at a quarterly frequency between 2018 and 2020, with the earliest data pertaining to $2004 \mathrm{q} 3$. As economic conditions rapidly deteriorated with the onset of the pandemic, the Census Bureau

\footnotetext{
${ }^{19}$ See Bayard et al. (2018) for details about the development of the
} BFS. 
Fig. 5 Monthly new business applications and (employer) business formations (indices $=1$ in 2006). Source Monthly BFS. Notes: Indices are relative to average in 2006 of each series. Likely employers $=$ HBA, Likely nonemployers $=$ BA-HBA, Business Formations is the spliced actual and projected series over the next eight quarters

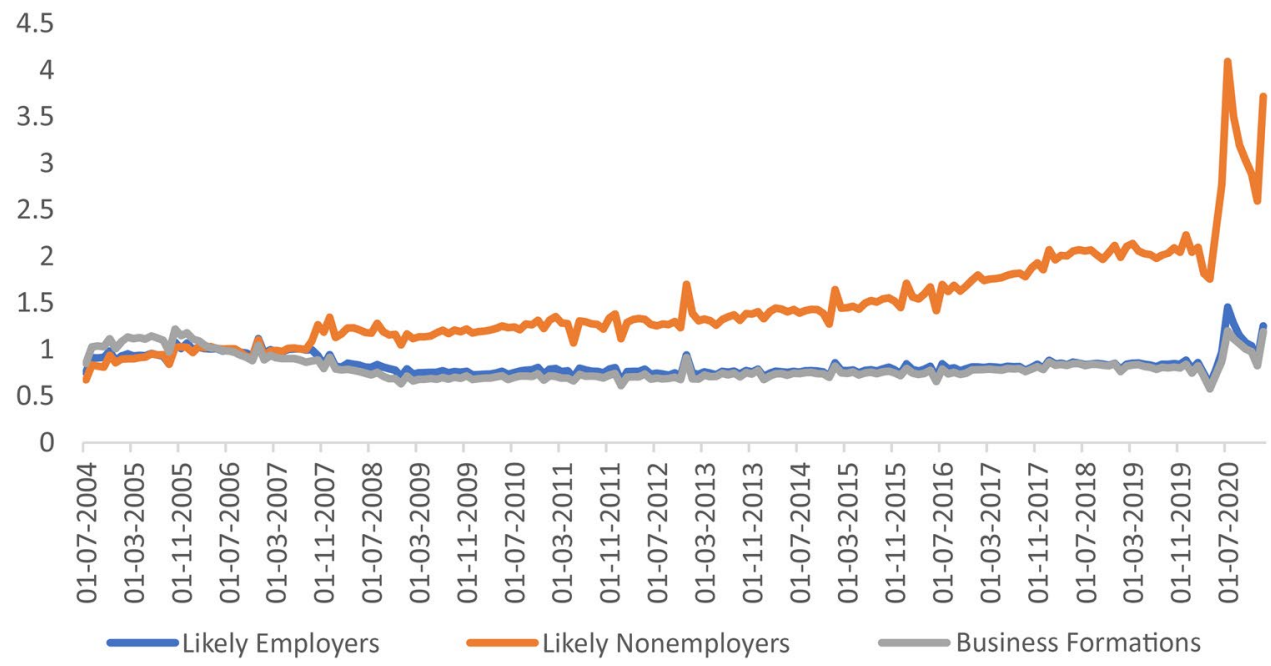

started releasing the BFS at a weekly frequency on April 8, 2020. The BFS has also initiated a monthly release starting in January 2021. Taken together, the weekly and monthly BFS offer unique high frequency, timely information on new business formations. Analysis of the weekly and monthly data reveals several striking patterns which we preview here and discuss in detail below. First, the COVID-19 recession has been very different from the Great Recession in terms of the short-run dynamics of business applications and projected formations. Second, there has been large variation across states and sectors in the patterns of business applications. Third, the surge in new business applications has been especially large for likely new nonemployer businesses but is also present for likely new employer businesses.

\subsection{Business applications and formations during the COVID-19 recession}

In terms of business cycle dynamics, Dinlersoz et al. (2021) investigate the weekly progression of business applications and projected business formations from these applications during the COVID-19 recession, and compare it with that during the Great Recession. They show that both business applications and formations exhibit a slow and protracted decline during the Great Recession. In contrast, they find that the drop in applications and projected formations is very sharp but short-lived during the COVID-19 Recession. Applications and projected formations both rebound very quickly, with the overall trajectory for the two series exhibiting a strong $\mathrm{V}$-shaped recovery.

While the transition rate from applications to employer businesses relative to the reference period also fell during the Great Recession initially, it recovered rapidly. Dinlersoz et al. (2021) find that after about 30 weeks from the onset of the recession, the cumulative transition rate went back up to its level in the reference period, and exceeded that level thereafter. The projected transition rates for the COVID19 Recession, on the other hand, had not recovered around the same time mark from the recession. The decline in the transition rate in the COVID-19 recession largely reflects a shift in the composition of applications towards those that are more likely to be new nonemployer businesses than new employer businesses.

These patterns are illustrated in Fig. 5, which uses the monthly BFS. Overall applications are decomposed into likely employers and likely nonemployers, where likely employers are High Propensity Business Applications, and likely nonemployers are the difference between overall applications and High-Propensity Business Applications. High-Propensity Business Applications (HBA) are defined using information provided on the EIN application including an indication of hiring employees; providing a date for first-wages paid or planned; providing a NAICS code in the Manufacturing, Health Care, Accommodation and Food Services sectors, or a portion of Retail Trade sector. ${ }^{20}$ The designation of HBA as likely employers and Non-High-Propensity Business Applications (NHBA) as likely nonemployers is consistent with Haltiwanger (2021), which provides evidence that variation in HBA closely tracks employer startups (which is evident in Fig. 5), and variation in NHBA closely tracks variation in nonemployer flows.

Overall applications and likely nonemployer applications are at the highest for the entire series in 2020, with the surge occurring in the second half of 2020. Interestingly, the surge continues into January 2021. For likely employers, there has also been a surge in 2020 but it is more muted. Still, applications for likely employers have had their highest year

\footnotetext{
20 The portion of Retail Trade classified in HBA is NAICS44, which is dominated by bricks and mortar stores. Applications for corporations are classified as HBA. For exact criteria see https://www.census. gov/econ/bfs/definitions.html.
} 


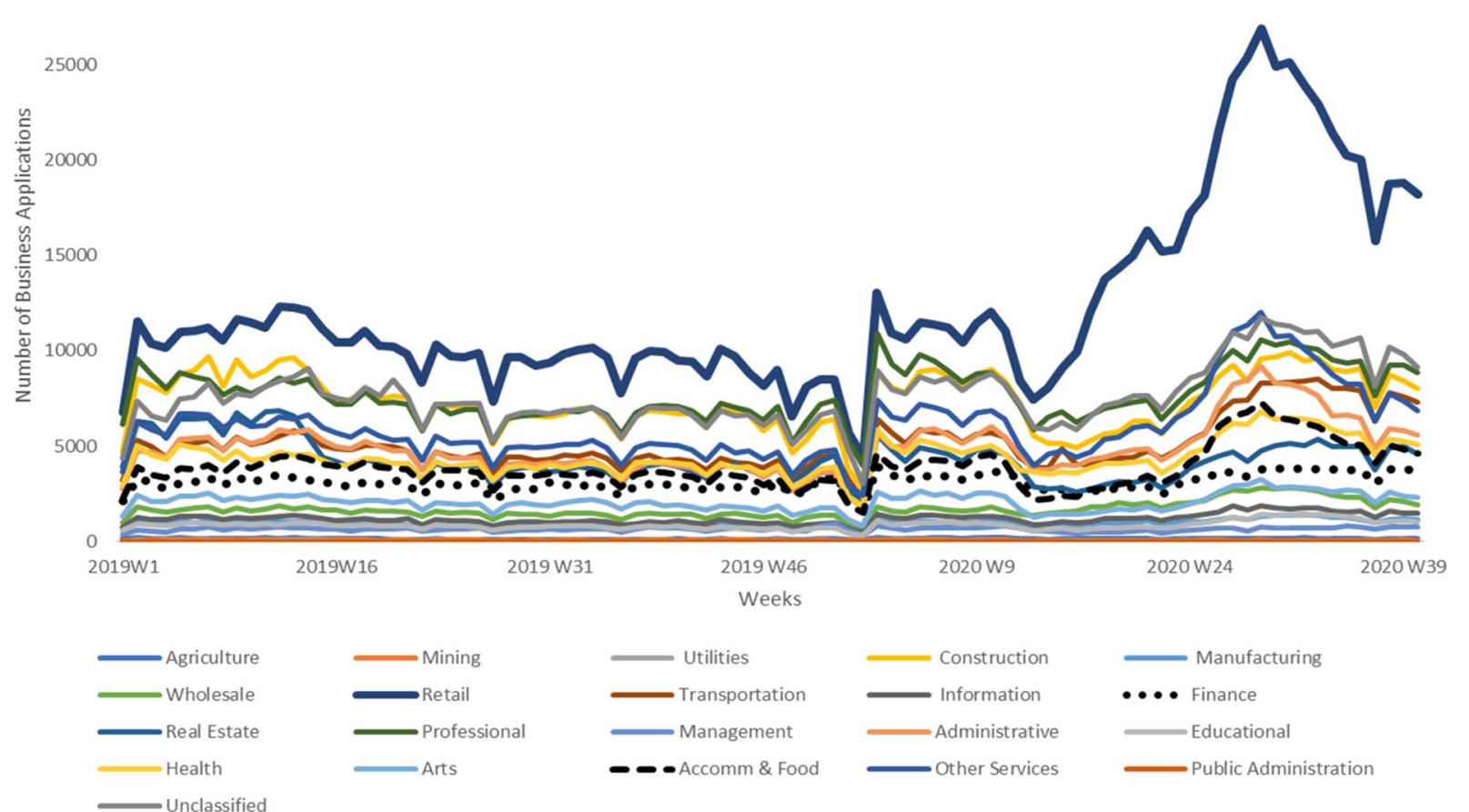

Fig. 6 Business applications by sector, weekly, 2019:w1 to 2020:w40. Source Special Projects, Business Formation Statistics https://www.census.gov/econ/bfs/projects.html

since 2006. This surge in applications for likely employers is important given the disproportionate role that new employer businesses play in job creation, innovation, and productivity growth (Decker et al. 2014). The surge in applications for likely nonemployers is potentially an acceleration of the shift towards the gig economy in the last decade or so, as emphasized in Abraham et al. (2021).

\subsection{Sectoral differences in applications during the COVID-19 recession}

The COVID-19 Recession has also been accompanied by large shifts in sector-level application activity. Initially, nearly all sectors experienced a sharp decline in business applications in the early phases of the recession (see Fig. 6). However, many sectors rebounded relatively quickly in application volumes, with a particularly large rise in retail (NAICS 44-45). A major component of that rebound in retail was accounted for by non-store retailers (NAICS 454), which includes mainly internet-based retail (part of e-commerce) activity. By mid-2020, the number of applications in this sub-sector exhibited an increase of more than $200 \%$ from its low in early 2020, before subsiding in the later part of the year. The surge of applications in this sub-sector far exceeded the other sub-sectors in retail.
The surge in non-store retailer applications is consistent with the push towards remote interactions between businesses and consumers in the pandemic. It is also broadly consistent with the pre-pandemic trend of increasing e-commerce. In this respect, this shift towards new businesses in the non-store retailer sector in the pandemic may reflect an acceleration of pre-pandemic trends. An open question is how many of these new non-store retailer businesses will be employers or nonemployers. Most of the businesses in non-store retail sub-sector have historically been nonemployers-in 2018 over $90 \%$ of non-store retailers were nonemployer businesses, based on combined Nonemployer Statistics (NES) and County Business Patterns (CBP) data. The public domain BFS includes the decomposition of BA into HBA and NHBA at the 2-digit NAICS level. ${ }^{21}$ Further

\footnotetext{
${ }^{21}$ An open question is the extent to which some of the surge in EINs are existing businesses adding a new line of business. It might be, for example, existing businesses add a new online line of business and apply for a new EIN for this activity. However, there is no requirement that adding a new line of businesses requires a new EIN for an existing business. Moreover, Decker et al. (2016) find multiple EIN firms are the exception, not the rule, and are concentrated among large, mature firms that operate in multiple states. Large, mature firms that operate in many locations account for a substantial share
} 
Fig. 7 Weekly business applications by state for 2020 , year-over-year growth rates $(\%)$. Source Business Formation Statistics
Business Applications by State

Year-over-Year Change (\%)

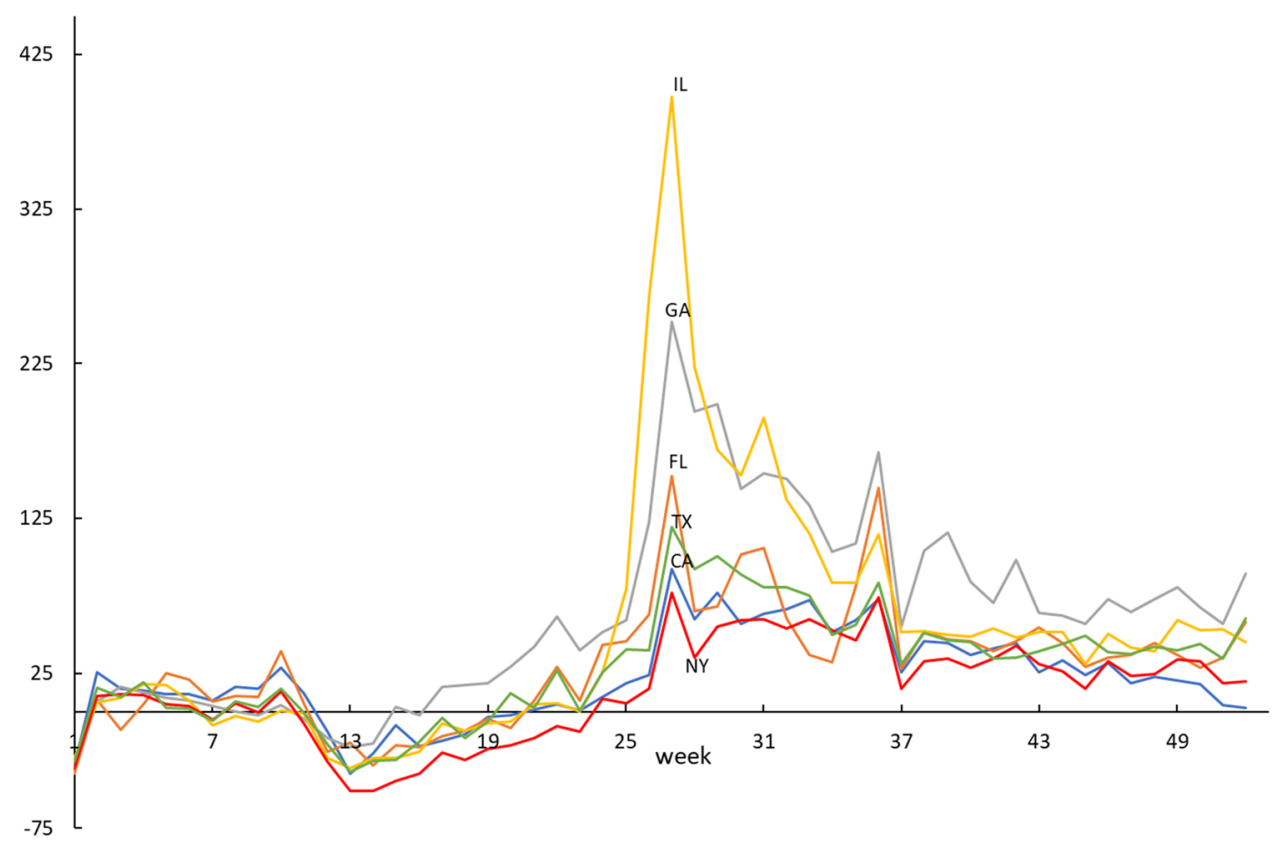

research (and time) is needed to understand the outcomes for the surge in applications for new non-store retailers.

The monthly data provide insights into the sectoral patterns decomposed for applications for likely nonemployers and likely employers. Haltiwanger (2021) shows there has been a surge in Retail Trade and Professional, Scientific and Technical Services in both types of applications. Existing small businesses in both sectors have had substantial declining revenue during the pandemic. The differing patterns for existing small versus new businesses suggest that the pandemic has induced considerable restructuring of business activity. An open question is how persistent these changes will turn out to be and whether any resulting businesses will have differing characteristics, such as scale, from those started during non-pandemic times.

\subsection{Geographic disparity in application activity during the COVID-19 recession}

The weekly BFS has been released for each state and Census Region, in addition to nationwide. Figure 7 shows the path of weekly year-over-year growth rates for business applications

\section{Footnote 21 (continued)}

of employment and revenue but a very small share of firms. Viewed from that perspective, it is very unlikely the share of multiple EIN firms has surged to the degree needed to account for surge in new EIN applications. It is also possible the surge in new EINs reflects in part existing businesses undergoing a change in ownership. An interesting area for future research is to explore the impact of the pandemic on ownership change of existing businesses. for selected states in 2020 (see Buffington et al. (2021a) for more analysis, including by region). New York, which experienced an early outbreak during the pandemic, exhibits a large decline in growth rate of applications heading into week 13. California, Texas, Illinois and Florida also went through declines initially, though less severe than in the case of New York. Georgia experienced much milder decline, a pattern that generally holds for other southern states. The recovery in applications was quite uneven. Illinois and Georgia had skyrocketing application growth, whereas the other states had more muted rebounds. Even New York, which experienced the largest decline initially, went from a 50\% deficit in applications in week 13 to a nearly $75 \%$ surplus in week 27, relative to the same weeks in 2019. Application growth generally recedes for all states featured in Fig. 7 after week 27. Nevertheless, Georgia and Illinois maintained high rates of growth compared to the other states in Fig. 7.

\section{Conclusion and future work}

The COVID-19 pandemic highlights the need for timely, high frequency, and geographically and sectorally granular socio-economic data. The SBPS provides information about an important part of the economy which was especially impacted by COVID-19: small businesses. The weekly and monthly BFS provide forward-looking information about an important driver of economic growth: employer business startups, which contribute to jobs and productivity. These 
two products capture temporal, sectoral, and spatial variation in the impact of the pandemic on the U.S. economy.

Phase 4 of the SBPS ended in April 2021 and Phase 5 began in May 2021. The new phases retain the core concepts of overall sentiment; changes in revenue, employment, and hours; and expectations. New concepts were added to capture the changing nature of the pandemic: business requirements for COVID-19 testing or vaccinations for onsite employees, changes in the physical footprint of the business, capital expenditures, business travel, and updates to the federal assistance programs. Less relevant concepts were removed to maintain the overall response burden.

One important area missing from these new data products requiring better measurement is business deaths. The SBPS is not well designed to capture business deaths, since survey nonresponse is likely greater for closed businesses. Existing research suggests that, similar to business births, business death may be best captured as a process. There may be extended periods of dormancy that, in some cases, eventually results in business death. Crane et al. (2020) highlight many different approaches to measuring business deaths, and these could be explored to complement Census Bureau data holdings, including administrative data on workers.

Moving beyond the publicly available data analyzed in this paper to the underlying micro level data, future research could focus on rich and complex dynamics at play over time, geography, and sector that can only be captured using the micro data. This micro data will be available to qualified researchers on approved projects in the Federal Statistical Research Data Center network. ${ }^{22}$ We hope this paper inspires others to use these rich sources of information.

\section{References}

Abraham, Katharine G., John C. Haltiwanger, Kristin Sandusky, and James R. Spletzer. 2021. Measuring the Gig Economy Current Knowledge and Open Issues. In NBER/CRIW Conference Volume on Measuring and Accounting for Innovation in the 21 st Century.

Bartik, Alexander W. Marianne Bertrand, Zoë B. Cullen, Edward L. Glaeser, Michael Luca, and Christopher T. Stanton. 2020. How Are Small Businesses Adjusting to COVID-19? Early Evidence from a Survey. NBER Working Paper No. 26989.

Bayard, Kimberly, Emin Dinlersoz, Timothy Dunne, John Haltiwanger, Javier Miranda, and John Stevens. 2018. Early Stage Business Formation: An Analysis of Applications for Employer Identification Numbers. NBER Working Paper No. 24364.

Bloom, Nicholas, Robert S. Fletcher, and Ethan Yeh. 2021. The Impact of COVID-19 on US Firms. NBER Working Paper No. 28314

Buffington, Catherine, Carrie Dennis, Emin Dinlersoz, Lucia Foster, and Shawn Klimek. 2020. Measuring the Effect of COVID-19 on

\footnotetext{
${ }^{22}$ Details about applying for access to the FSRDC network can be found at: https://www.census.gov/programs-surveys/ces/data/restr icted-use-data/apply-for-access.html.
}

U.S. Small Businesses: The Small Business Pulse Survey. Center for Economic Studies Working Paper No. 20-16.

Buffington, Catherine, Daniel Chapman, Emin Dinlersoz, Lucia Foster, and John Haltiwanger. 2021a. High Frequency Business Dynamics in the United States During the COVID-19 Pandemic. Center for Economic Studies Working Paper No. 21-06.

Buffington, Catherine, Jason Fields, and Lucia Foster. 2021b. Measuring the Impact of COVID-19 on Businesses and People: Lessons from the Census Bureau's Experience. AEA Papers and Proceedings 111: 312-316. https://doi.org/10.1257/pandp.20211047.

Crane, Leland D., Ryan A. Decker, Aaron Flaaen, Adrian HaminsPuertolas, and Christopher Kurz. 2020. Business Exit During the COVID-19 Pandemic: Non-Traditional Measures in Historical Context. Finance and Economics Discussion Series No. 2020089. Board of Governors of the Federal Reserve System. https:// doi.org/10.17016/FEDS.2020.089.

Decker, Ryan, John Haltiwanger, Ron Jarmin, and Javier Miranda. 2014. The Role of Entrepreneurship in US Job Creation and Economic Dynamism. Journal of Economic Perspectives 28 (3): 3-24.

Decker, Ryan, John Haltiwanger, Ron Jarmin, and Javier Miranda. 2016. Where has all the Skewness Gone? The Decline in High Growth (Young) Firms in the U.S.? European Economic Review 86: 4-23.

Dinlersoz, Emin, Timothy Dunne, John Haltiwanger, and Veronika Penciakova. 2021. Business Formation: A Tale of Two Recessions. AEA Papers and Proceedings 111: 253-257.

Goolsbee, Austan and Chad Syverson. 2020. Fear, Lockdown, and Diversion: Comparing Drivers of Pandemic Economic Decline 2020. Journal of Public Economics 193(C).

Haltiwanger, John. 2021. Entrepreneurship During the COVID-19 Pandemic: Evidence from the Business Formation Statistics. Paper for Presentation at the NBER Entrepreneurship, Innovation and Economic Policy Conference, April.

National Federation of Independent Businesses. 2020. Covid-19 Small Business Survey (14): PPP, EIDL, the Economy and the Vaccine. December 6-11. https://assets.nfib.com/nfibcom/Covid-19-14Questionnaire-Write-up-FINAL-Web.pdf

Publisher's Note Springer Nature remains neutral with regard to jurisdictional claims in published maps and institutional affiliations.

Catherine Buffington is a Senior Advisor for Economic Programs at the Census Bureaus and most recently served as the Director of the Small Business Pulse Survey in 2020. Ms. Buffington collaborates with internal and external researchers to develop new statistical data products. She has served on teams that were twice awarded the Director's Award for Innovation and twice awarded the Census Bureau's Bronze Medal. Ms. Buffington has a B.A. in Economics from NC State University and an M.A. in Economics from the University of Maryland.

Daniel Chapman is a Research Assistant at the Census Bureau under the Economic Measurement and Research Internship program. Daniel is a rising fourth-year PhD student in Economics at the University of Maryland, College Park, with interests in economic history and public finance. He holds a B.A. in Economics and Math from The University of Texas at Austin.

Emin Dinlersoz is a Principal Economist in the Center for Economic Studies (CES) at the U.S. Census Bureau. Dr. Dinlersoz uses Census Bureau micro data to conduct research in industrial organization, entrepreneurship, technology, labor economics, and applied microeconomics. Dr. Dinlersoz was awarded a U.S. Department of Commerce Silver Medal as a team member for developing the Business Formation Statistics and two Census Bureau Bronze Medals as a team member 
for work on the 2010 Decennial and 2012 Economic Census. Prior to joining the Census Bureau, Dr. Dinlersoz was a Senior Economist at Cornerstone Research and an Assistant Professor of Economics at the University of Houston. He has a B.S. in Industrial Engineering from Bilkent University and a Ph.D. in Economics from the University of Rochester.

Lucia Foster is the Chief Economist of the Census Bureau and Chief of the Center for Economic Studies (CES). In this role, she leads the economic research groups within CES, including the Longitudinal Employer-Household Dynamics (LEHD), Business Research, Interdisciplinary Research, and Demographic Research. Dr. Foster uses Census Bureau micro data to conduct research on productivity and reallocation, management practices, and R\&D performing firms. Dr. Foster was awarded a U.S. Department of Commerce Gold Medal as a team member for the Federal Statistical Research Data Centers, a Census Bureau Bronze Medal as a team member for the Annual Survey of Entrepreneurs, and a Census Bureau Bronze Medal as a team member for work on the 2010 Decennial. She has a B.A. in Economics from Georgetown University and a Ph.D. in Economics from the University of Maryland.
John Haltiwanger is a Distinguished University Professor in the Department of Economics at the University of Maryland. He is also the first recipient of the Dudley and Louisa Dillard Professorship in 2013. He received his Ph.D. from the Johns Hopkins University in 1981. After serving on the faculty of UCLA and Johns Hopkins, he joined the faculty at Maryland in 1987. In the late 1990s, he served as Chief Economist of the U.S. Census Bureau. He is a Research Associate of the National Bureau of Economic Research, a Senior Research Fellow at the U.S. Census Bureau, and a Fellow of the Society of Labor Economics and the Econometric Society. He has played a major role in developing and studying U.S. longitudinal firm-level data. Using these data, he has developed new statistical measures and analyzed the determinants of firm-level job creation, job destruction and economic performance. He has explored the implications of these firm dynamics for aggregate U.S. productivity growth and for the U.S. labor market. The statistical and measurement methods he has helped develop to measure and study firm dynamics have been increasingly used by many statistical agencies around the world. His own research increasingly uses the data and measures on firm dynamics from a substantial number of advanced, emerging and transition economies. His work with the statistical agencies has been recently recognized in his being awarded the Julius Shiskin Award for economic statistics in 2013, the Roger Herriott Award for innovation in federal statistics in 2014, and the Global Entrepreneurship Research Award in 2020. He has published more than 100 academic articles and numerous books including Job Creation and Destruction (with Steven Davis and Scott Schuh, MIT Press). 